\title{
CONTRIBUCIÓN ÉTICA Y ECOMUNITARISTA A LA ANTROPOLOGÍA FILOSÓFICA: CAPITALISMO Y ALIENACIÓN EN EL SIGLO XXI
}

\author{
Sirio López Velasco
}

Universidade Federal do Rio Grande-FURG, Brasil

RESUMEN: En este trabajo intentamos dar, en la perspectiva de la ética y de la propuesta ecomunitarista, un aporte a la antropología filosófica en el siglo XXI, a partir de la explicitación y crítica de diversas dimensiones de la alienación padecida por los individuos en el capitalismo.

Palabras clave: Ética, ecomunitarismo, alienación, antropología filosófica, capitalismo.

\section{ETHICS AND ECOMMUNITARIANIST CONTRIBUTION TO PHILOSOPHIC ANTHROPOLOGY. CAPITALISM AND ALIENATION IN XXI CENTURY}

ABSTRACT: This paper try, on de basis of ethics and ecommunitarianist approach, a contribution to philosophic anthropology in the XXI century, since the explanation of diverse expression of the individual alienation in the capitalism.

Keywords: Ethics, ecommunitarianism, alienation, anthropological philosophy, capitalism.

\section{Introducción}

En este trabajo nos proponemos repensar la antropología que Paulo Freire presenta al principio de su "Pedagogia do Oprimido", y lo hacemos apoyándonos en Marx y enfocando la realidad capitalista del siglo XXI y la alternativa 
latinoamericana del socialismo del siglo XXI en perspectiva ecomunitarista. Para tanto partimos de las tres normas fundamentales de la ética, deducidas argumentativamente de la gramática profunda de la pregunta que la instaura. Como se sabe Freire consideró que el capitalismo impide la "vocación de ser más de los seres humanos", en especial de los oprimidos (que en los ejemplos de la "Pedagogía del Oprimido" son los trabajadores y campesinos). Aquí nos proponemos alargar esa visión detallando las limitaciones que impone al pleno desarrollo de los individuos la vigencia del trabajo alienado capitalista, y exponiendo otras facetas del individuo que constituye muchas mayorías de las sociedades capitalistas actuales (en especial en A. Latina). Para terminar resumimos algunas ideas acerca de la alternativa ecomunitarista y del socialismo del siglo XXI, creados en América Latina.

\section{La ética y sus tres normas fundamentales}

La ética se constituye a partir de la pregunta "¿Qué debo hacer?"

Como se sabe, hemos reformulado las normas éticas como Cuasi-Razonamientos Causales, que comienzan por una obligación del tipo "Debo x", a la que sigue el operador no veritativo "porque" e inmediatamente un enunciado falseable que retoma el " $x$ " de la obligación inicial y que le sirve de justificación argumentativa; así la ética es argumentada y no dogmática, y se reorganiza según lo que en cada momento histórico consideremos falseado o no. La gramática del CRC es la que sigue: mientras no sea falseado el enunciado que justifica la obligación, ésta mantiene su vigencia; y la pierde cuando es falseado aquél enunciado; entonces se abre el espacio-tiempo de la búsqueda de otra obligación capaz de sustituir a la primera, con un enunciado no falseado que la justifique.

Al mismo tiempo, en base a la "felicidad" de los actos lingüísticos propuesta por Austin (Austin 1962), y al operador de "condicional", hemos deducido argumentativamente interrogando las condiciones de felicidad de la pregunta que instaura la ética ("¿Qué debo hacer?"), tres normas éticas fundamentales de validez intersubjetiva universal (por lo menos al interior de la llamada "cultura occidental" y su área de influencia) que nos obligan, respectivamente a luchar para garantizar nuestra libertad individual de decidir, vivenciar esa libertad en búsquedas de respuestas consensuales para cada instancia de la pregunta acerca de lo que debo/debemos hacer, y a preservar-regenerar la salud de la naturaleza humana y no humana.

\section{La ética, el concepto de "liberación" y el ecomunitarismo}

Sobre la base de las tres normas de la Ética defino la Liberación como un proceso histórico de construcción de la libertad consensual de decisión acerca 
de nuestras vidas, a través de la discusión y de la lucha contra las instancias de dominación intersubjetiva y auto-represión alienada; proceso del cual hace parte la construcción de relaciones productivas y estéticas de carácter preservadorregenerador entre los seres humanos y el resto de la Naturaleza.

El ecomunitarismo (nunca alcanzable, pero indispensable estrella-guía) representa la efectiva constitución histórico-real del género humano en una asociación planetaria de productores libremente asociados (Marx 1844) que satisfacen solidariamente las necesidades del desarrollo multifacético de cada uno en un intercambio preservador-regenerador con la naturaleza no-humana. [Como cito y citaré diversas veces a Marx porque mucho me inspira su posición críticoutópica ante el capitalismo, es bueno aclarar que mi posición, fundamentada en las tres normas antes deducidas, es por completo independiente del éxito o fracaso de las tesis centrales de Marx referentes a la plusvalía, la tasa de ganancia y su disminución].

En el ecomunitarismo las "órdenes" y toda relación impositiva asimétrica han sido superadas por los acuerdos consensuales, que rigen a) a nivel erótico, transformado en dimensión del encuentro de dos libertades que comparten el placer, b) en lo pedagógico, con la superación de la educación "bancaria" por la "problematizadora" (Freire 1970), c) en la política, devuelta a su sentido original de "conjunto de ciudadanos que organizan la polis", practicando la democracia directa y sometiendo a las bases las funciones representativas que se hicieren necesarias, $y$, a nivel mundial, sustituyendo la actual ONU por una efectiva asamblea cooperativa de pueblos, aboliéndose el actual abismo entre naciones "decididoras" y "no-decididoras", que se expresa en el derecho de veto y la dominación militar, y, d) en la comunicación simétrica, que supera la asimétrica existente hoy a través de los grandes medios privados y seudo-públicos de comunicación.

\section{La condición humana en el capitalismo: la alienación en la producción capitalista (ver López Velasco, 2012)}

Consideramos un hecho que la gran mayoría de los individuos actuales vive en un contexto capitalista, e intentaremos mostrar (apoyándonos en Marx), cómo en éste rige el trabajo alienado. "Estar alienado de" significa "estar separado de", como lo entiende la terminología jurídica al considerar como un acto de alienación, la separación de un bien que ocurre en una venta, cesión o préstamo, mas resulta claro que lo que preocupa a Marx en su crítica al capitalismo es el hecho de que en ese modo de producción y de vida, el individuo (en especial el obrero, pero también el capitalista y sus representantes), se encuentra mutilado e impedido de desarrollarse como individuo universal (o sea, desarrollado en todas sus vocaciones y aptitudes) porque se encuentra separado (o sea "alienado") de diversos modos: del otro individuo, con y no contra cuya libertad debería rea- 
lizarse la suya propia, de sí mismo, y de múltiples instancias donde se dan y/o plasman las relaciones interindividuales.

No olvidemos que Marx, siguiendo a Aristóteles (para quien el ser humano es un ser político), considera al individuo como un nudo de la rede de relaciones sociales en las que está insertado. Ahora bien, para Marx la relación económica fundamental existente en el capitalismo es la que une-opone a los dueños de los medios de producción (capitalistas) a sus asalariados (no propietarios de medios de producción). Al mismo tiempo sostuvo que en el capitalismo la producción es guiada por la valorización del valor (el dinero invertido en fuerza de trabajo y medios de producción debe generar un producto cuya venta arroja un dinero de valor superior al inicial). Consideramos que las observaciones marxianas acerca de la alienación realizadas en "El Capital", pueden ser subsumidas en una y/o en otra de las tres normas fundamentales deducidas en nuestra ética argumentativa ecomunitarista.

Así, por ejemplo, postulamos como hipótesis que quizá podrían ser subsumidas, entre otras: a) por la primera norma, diversas limitaciones a la libertad individual impuestas por la alienación en relación a sí mismo, al trabajo, al producto del trabajo y a la actividad productiva , b) por la segunda norma, diversas violaciones del consenso impuestas por la alienación en relación a los medios de vida y de producción, a la actividad productiva y en las relaciones interindividuales de producción y de comunicación existentes en la empresa capitalista (marcada por la preponderancia del acto lingüístico de la "orden"), y c) por la tercera norma, diversos atentados a la salud de la naturaleza humana y no humana impuestos por la alienación en relación a sí mismo y al otro, a los medios de producción y de vida, a la actividad productiva y a la naturaleza no humana.

La alienación en relación al trabajo consiste en el hecho de que no es el trabajador quien decide si va a trabajar o no, sino que depende de la voluntad del capitalista (o un representante de éste) que se digne contratarlo; de esa circunstancia deriva el hecho de que en el capitalismo el desempleo es siempre una espada de Damocles que pende sobre la cabeza del asalariado.

La alienación en relación al producto del trabajo consiste en el hecho de que lo producido por el asalariado no le pertenece, sino que pertenece al capitalista; el trabajador sólo podrá reencontrarse con los frutos del trabajo (y ello en los límites del poder adquisitivo de su salario) por la vía indirecta que es la del poder de compra del monto que recibe del capitalista a cambio del valor de su fuerza de trabajo.

La alienación en relación a la actividad productiva consiste en el hecho de que cuando el trabajador tiene la "fortuna" de ser contratado por algún capitalista, su actividad productiva no se desarrollará según sus vocaciones, sino según la orden proveniente del capitalista (o un representante suyo) que le adjudica una función (que, como regla, es repetitiva y unilateralizante).

En esas condiciones es fácil percibir que, a partir del momento en el que vendió su fuerza de trabajo, el asalariado ya no se pertenece a sí mismo, y de ahí el hecho de la alienación en relación a sí mismo. 
Paralelamente, en el capitalismo la distribución de los medios de producción (y los de vida, que de ellos dependen), no se da para cada generación e individuo a partir de deliberaciones consensuales, sino que resulta de una división clasista que los precede (la existente entre los dueños de los medios de producción, o sea los capitalistas, y los que de ellos están privados, o sea los asalariados).

Al mismo tiempo, las relaciones comunicativas en cada empresa (rural o urbana) no están signadas por la dinámica consensual, sino por "órdenes" que emanan del capitalista (o un representante), a las que el asalariado debe obedecer, so pena de perder su empleo y con él la fuente de sus medios de subsistencia.

Finalmente, en el capitalismo la tierra ha sido privatizada en manos de una minoría (los terratenientes que se unen e incluso se funden con los capitalistas) y la naturaleza no humana deja de ser para las grandes mayorías asalariadas o excluidas del empleo fuente de alimentos y recursos para satisfacer otras necesidades vitales. En eso consiste la alienación entre los asalariados y desempleados, por un lado, y la naturaleza no humana del otro. $\mathrm{Y}$ simultáneamente en ese contexto, sufre la salud del trabajador (naturaleza humana) por las condiciones laborales que le impone el capitalista, y sufre con la devastación y la contaminación galopante (que amenaza ser irreversible) la naturaleza no humana, víctima de la externalización de costos ambientales que es inherente a la férrea lógica de valorización del valor que caracteriza a la economía capitalista.

En esa economía fetichizada, los sujetos son objetivados y las mercancías son sujetos en un mercado que avanza sobre todas las facetas de la vida humana, y que se personifica al punto de que la TV un día sí y el otro también nos habla del "humor del mercado" o de "lo que espera o quiere el mercado", atestiguando así que las relaciones interpersonales que deberían estar basadas en la libertad individual, las decisiones consensuales y la vigilia de la salud de la naturaleza humana y no humana, se han convertido en una seudoentidad objetiva que a los humanos se impone, para sojuzgarlos.

Es en ese contexto en el que denunciaba Marx que el ser social determina la consciencia, no sin defender la idea de que en la alternativa comunista habría de ocurrir lo contrario; por nuestra parte incorporamos completamente esa idea en nuestra propuesta ecomunitarista.

\section{Resumen sobre la violación de las normas fundamentales de la ética en la alienación económica capitalista}

En la medida en que en esa célula fundamental del trabajo alienado en el capitalismo que es la empresa, el trabajador está siempre sometido a las órdenes del capitalista (ordenes cuya "felicidad" el asalariado debe reconocer siempre so pena de perder su empleo), es evidente que el día a día del capitalismo niega al asalariado el ejercicio da su libertad individual de decisión y su participación en la construcción de propuestas consensuadas. En el capitalismo se espera del 
trabajador, lo mismo que del soldado, o sea, que no piense, sino que obedezca. Como dijo Marx, en el contexto del trabajo alienado el asalariado pasa a ser una "cosa" más (como lo son el instrumento y el objeto de trabajo) perteneciente al capitalista; y el capitalista cree estar en lo cierto cuando concluye que esa "cosa" como cualquier otra está incapacitada para la libertad de decisión que es amparada por la primera norma de la ética.

El capitalismo es una orden social de "guerra de todos contra todos"; guerra de capitalistas contra capitalistas (aunque se alíen contra los asalariados y puedan aliarse entre sí en carteles para guerrear contra otros carteles); guerra de los capitalistas contra los asalariados (en especial a causa del monto del salario, de las condiciones del trabajo y de la duración de la jornada do trabajo); y guerra de asalariados contra asalariados (en particular en la lucha por la conquista y manutención del empleo). En esas circunstancias es evidente que estamos muy lejos de la construcción consensual de respuestas exigida por la segunda norma de la ética.

Al mismo tiempo esa guerra se acompaña de la indiferencia creciente de cada ser humano para con los otros en el egoísmo creciente que el capitalismo causa e incentiva al glorificar la competencia. Hoy hay pesquisas que muestran que el crecimiento de esa indiferencia acompaña al desarrollo capitalista; así, un actor que finge sentirse mal en la calle, es atendido por casi todos en la pequeña ciudad (de capitalismo comercial incipiente y rodeada de un campo donde todavía hay ecos de vivencias pre-capitalistas), es atendido por pocos en la ciudad media (la del comercio y la industria medianos), y por casi nadie en la gran urbe (centro del gran capital financiero, comercial e industrial).

Los efectos nocivos para la naturaleza resultantes de la continuidad del modelo de producción-distribución-consumo imperantes hoy en día, provocan una degradación cuantitativa y/o cualitativa de tal magnitud en el medio ambiente que hace posible la vida humana, que la propia subsistencia de la humanidad corre peligro. Ese peligro es reconocido incluso en foros tan marcados por la influencia directa de los grandes capitales como lo es el "Club de Roma". La amenaza de un holocausto ecológico y/o nuclear capaz de exterminar la humanidad entera es una situación absolutamente inédita en la historia de la especie humana.

Ahora bien, aquí quiero destacar en primer lugar que la incertidumbre en relación a la obtención y manutención del empleo, el nivel de exigencia en la actividad productiva y los peligros existentes en ella (velocidad de la línea de producción, y/o nivel de tensión-atención permanente, y/o falta de equipos y medidas de seguridad) y los efectos contaminantes de la producción capitalista Ilevan literalmente a los asalariados a enfermarse. Diversas pesquisas muestran el estrago que en las masas asalariadas causan los accidentes de trabajo (muchas veces mortales, en especial en las industrias de la construcción y del transporte), las enfermedades diversas causadas por la contaminación de la tierra, el agua y el aire (hecho evidenciado en la correlación existente entre la mayor mortalidad 
por problemas circulatorios/respiratorios en una ciudad como São Paulo y el mayor nivel de contaminación del aire que allí se respira), y las enfermedades físicas y/o mentales debidas al estres. Una y otra evidencia (en el contexto del trabajo alienado capitalista) son contrarias a la salud de la naturaleza humana, y por eso son contrarias a la tercera norma ética.

En lo que respecta a la salud de la naturaleza no-humana, son hoy ya indiscutibles los estragos que le causa la producción-distribución-consumo capitalista basada en el trabajo alienado. A tal punto, como dijimos, que el envenenamiento progresivo de la tierra, del aire y del agua, hace peligrar la supervivencia futura de la propia especie humana (por lo menos en las áreas más contaminadas). Al mismo tiempo se verifica una clara devastación del espacio geográfico: deforestación irreversible (hoy especialmente en las grandes florestas tropicales), desertificación y salinización de inmensas áreas a causa de usos agrícolas no sustentables, uso insostenible de recursos minerales y energéticos no renovables (todo indica que el petróleo se acabará antes del siglo XXII), y la mismísima agua potable ya empieza a faltar en muchos países o regiones de países. Si el ciclo del agua ya está afectado a ese punto, no menos afectado lo está el ciclo del carbono, porque emisiones masivas derivadas del modo capitalista de producción-distribución-consumo (copiado antes por el Ilamado "socialismo real" difunto en Europa desde 1991) generaron el "efecto invernadero" que está alterando el clima mundial a causa de un calentamiento de la temperatura en el planeta (con el derretimiento de los hielos polares y el consecuente aumento del nivel de los océanos y variación de corrientes marinas, cuyos efectos son todavía incalculables en detalle); otros gases generados por la producción-distribución-consumo capitalista aumentan el agujero en la capa de ozono, lo que se traduce en un aumento de la radiación ultravioleta que alcanza la superficie terrestre (con los peligros que ello conlleva, como el aumento de los cánceres de piel, ya detectado en el sur de Brasil); al mismo tiempo la producción-distribución-consumo capitalista pone en riesgo de extinción cada día a más y más especies vegetales y animales.

\section{Más allá de la alienación económica: otras dimensiones del pobre individuo del capitalismo actual (ver López Velasco 2009)}

En lo que sigue me propongo explicitar algunos rasgos característicos de la vida individual en la fase actual del capitalismo incorporando a la utopía de la lucha de liberación que tiene al Ecomunitarismo como horizonte regulador, algunos hechos que dan pie a la propuesta posmoderna cuando ésta reacciona con lucidez a ciertos cuellos de botella mayores de la Modernidad. De hecho lo que habré de hacer es proceder a un ajuste de cuentas con mis contemporáneos en el seno de la llamada "cultura occidental" (que es la que conozco), teniendo claro que, por lo menos en parte, en esos Otros se refleja mi propio "yo". 


\section{El individuo aturdido-confuso-disperso}

Por las grandes y pequeñas ciudades y cada vez más también en los campos de la cultura llamada "occidental" y allí donde el capitalismo generado por ésta ha llegado, deambulan millones de individuos aturdidos por una sinfonía gritante de propaganda e informaciones, sin que la diferencia entre ambas sea clara. Al contrario, el análisis muestra que las informaciones que se suceden atropelladamente unas a otras no son más que los intervalos intercalados entre el flujo de publicidad e intereses económico-político-militares más o menos camuflados, cuando no la expresión implícita de estos últimos y aún mensajes publicitarios más eficaces porque identificados con "los hechos", a saber, con lo fáctico de un cotidiano que de más en más aparece como, lo "natural-inevitable". En medio de ese bombardeo el individuo se dispersa entre mil estímulos y no acierta a unificar su vida, ni siquiera a ponerla bajo su control. Esta es la culminación de la división de la Razón registrada por la trilogía de las "Críticas" kantianas y el estadio actual de la vivencia de ruptura existencial que, haciendo eco a Hume, confesaba sin querer Bertrand Russell cuando constataba que su razón práctica nada tenía que ver con lo establecido por su filosofía (marcada por la impronta del atomismo lógico moldeado según el paradigma de la reducción del lenguaje a las esferas compatibles con el poder instrumental de la lógica clásica, o sea, a los "enuncia$\left.\operatorname{dos}^{\prime \prime}\right)$. Y allí va ese individuo, aturdido, confuso y disperso, zigzagueando en la vida al sabor de las modas sucesivas que poco duran y no lo sacan de su angustia y su sentimiento de "perdidos en la noche".

\section{El individuo solo a merced de la indiferencia, la competencia y la violencia}

Pero no solo la noche es hostil. También lo es el día. En uno y en otra se instala la soledad. Claro que ésta pesa más en la noche y ni siquiera los teléfonos del "disque amistad" pueden evitar muchas veces el suicidio de ese individuo solo y perdido en el mundo. La profunda transformación de la familia surgida con el capitalismo, que la reduce a un núcleo cada vez menor, que termina por resumirse a la pareja (aún cuando ésta tenga hijos) e incluso a un mutuo aislamiento vivido a dúo, ha creado una de las causales de esa soledad.

El otro fundamento opera tanto dentro como fuera de los anteriores nexos familiares pues la condición de mutuos competidores que pasa a ser la de los individuos en el capitalismo, sean ellos capitalistas o asalariados, origina la hostilidad que decreta la soledad de cada uno de los contendores. Esa soledad es producto y causa, a su vez, de la indiferencia generalizada que se instala y que investigaciones empíricas demuestran que aumenta en proporción directa con el grado de "capitalización" de las relaciones sociales. Esa soledad alimentada por la competencia y la indiferencia es la que hace al individuo volcarse sobre sí mismo y, lo que no es incompatible con esa postura egoísta, buscar, muchas veces con la ayuda de las drogas que permiten olvidar por momentos el duro día a día, 
la compañía superficial de otros "perdidos en la noche"; pero la paradoja que resulta de esa búsqueda es que ni siquiera las soledades son compartidas, porque la relación superficial y de uso del Otro que se establece en esas circunstancias, a lo más autoriza a hablar de la reunión de dos soledades que, no por reunidas, dejan de aislar a cada sujeto en la suya propia. Esta soledad brutal es la expresión real-actual de aquel atomismo del "cogito" que Descartes, sin duda reflejando un hecho real que comenzaba a suceder con los albores del capitalismo, fundamentó en un Sujeto para el cual la existencia de "otras mentes" además de la suya no pasaba de una hipótesis ardua frente a la semejanza existente entre los autómatas y los seres que ante el Ego "parecen" dotados de cualidades humanas. Parece un hecho indiscutible, por fin, que esa soledad no puede separarse de los efectos provocados por el uso dominante de los modernos medios de comunicación. En efecto, primero la radio y después la TV propiciaron un encerramiento de los individuos en sus casas, eliminando viejas prácticas de convivencia familiar y barrial pautadas por las largas y frecuentes veladas de conversación, arte y diversiones compartidas. Familias e individuos se encerraron en sus casas, incluso en sus respectivas habitaciones, y es increíble cómo aún en presencia de un núcleo humano, basta la activación de un aparato de televisión para que los individuos se vean mutuamente separados por éste. Lo que antes era diálogo se divide en tantos monólogos como individuos haya, con la particularidad de que quien habla es sólo el aparato y cada uno de los antiguos dialogantes es transformado en mero oyente.

Creo por demás claras las evidencias de que nuestra cultura capitalista actual desarrolla la propensión a la soledad ya desde la infancia. No sólo por el contenido de los mensajes de indiferencia y competitividad-hostilidad que los niños reciben diariamente de los adultos, en especial a través de los medios de comunicación; también porque la propia forma de sus juegos (y esto no existía en mi propia niñez en los años 50 y 60) es la del aislamiento. Sus seudo-compañeros de juegos no son otros niños sino la televisión, la computadora y el play station.

La violencia es la culminación de todo ese panorama. ¿Qué otra cosa se podría esperar de individuos que desde niños la maman en su casa, en la enseñanza para la agresividad y la competitividad que reciben en la escuelas y Universidades donde pasan su infancia, adolescencia y inician su madurez, y la padecen día a día en la guerra general donde transcurre la actividad productiva mediante la cual intentan garantizar su subsistencia?

De tanta soledad atomísticamente cultivada en mutua oposición en relación al Otro no sería lógico esperar la dulzura en vez de la violencia. (No olvidemos que la violencia capitalista primigenia es la imposibilidad que existe en el capitalismo de que las personas se desarrollen como individuos universales, realizando todas sus potencialidades y vocaciones, y que la misma se muestra con toda su crueldad cuando aparece como hambre u otras formas de padecimiento físicomental). 
Es obvio que la TV y las películas tienen su parte en la carnicería cotidiana, pero pecan por ingenuidad o mala fe aquellos que no ven que la propia TV y la cinematografía no son más que una parte y una expresión (tal vez menos cínica que sus críticos) de la totalidad violenta que es el capitalismo. Entre tantas otras cosas él es el día a día de la prevención con el extraño que lleva a los padres a aconsejar a los niños que no acepten nada de desconocidos, porque los propios padres no se detendrán a socorrer a ningún extraño que vean en mal trance; él es el contexto donde florecen las rejas y los sistemas de alarmas, efecto boomerang de la competitividad agresiva que pregona a cuatro voces como modelo comportamental; él es el que hace de las drogas y las armas el comercio más lucrativo de la actualidad. Y al calor de la droga, el individuo solo, perdido y frustrado, pierde los frenos del "superyo" que nada a contra-corriente del día a día, y descarga su energía en la violencia que ahora, ni siquiera necesita ser motivada por razones de subsistencia como ocurre con el robo y el asalto. El "no me gustó su cara" o incluso el acaso de dos trayectorias que se cruzan en una calle oscura y sucia, será motivo suficiente para la cuchillada o el disparo a quemarropa. Y allá se va una vida como se va un pucho a medio fumar. Una muerte más que nunca nadie aclarará. Cuando el otro es el indio, el negro, el turco, el árabe, el judío, o simplemente el extranjero, ese mismo individuo solo, perdido, frustrado y ahora también desempleado, azuzado por los führers cobardes de siempre, tendrá incluso la disculpa del "bienestar" de los connacionales para ejercer la violencia que lo desborda. Y tanto su acto como la crítica cursi de los burgueses "demócratas" servirá para que el capitalismo siga girando en torno a su eje, sin olvidar que esos mismos críticos pueden unirse a los que ahora critican si el peligro "rojo", hoy "rojiverde", se cierne sobre ese planeta sagrado.

\section{Individuo y culto al cuerpo sin cabeza}

Ese individuo solo, aturdido, confuso y disperso, alentado por el modismo de un neo-hedonismo acoplado a la venta de infinitos productos de "belleza", se vuelve sobre sí mismo para captarse como individuo sólo a través del cuerpo. Mas esa captación es represiva. De ahí los sudores y sufrimientos diversos a los que se somete acicateado por los "modelos" hollywoodianos de la silueta perfecta, en largas y continuas sesiones de "academias" de gimnasia, de masajes y bronceado (¡Si Platón supiera dónde ha venido a parar la "Academia"!). Y para que el espectáculo sea completo no ha de faltar la dieta y sus múltiples productos, en un mundo donde buena parte de la humanidad aún no logra saciar el hambre. ¡Bello espectáculo el de una cultura en la que los individuos se dividen entre los que mueren por no comer lo suficiente y los que luchan contra el exceso (real o supuesto, según el "modelo") de peso y cuando éste es real, mueren por comer demasiado! En este esteticismo degradado del cuerpo sin alma no hay espacio para la "mente sana" ("en cuerpo sano") y la propia sanidad del cuerpo está envuelta por la enfermedad del individuo alienado del que forma parte. 
En ese contexto se ve también degradada la práctica deportiva al pasar ésta a hacer parte de la red de las mercancías que circulan y de las relaciones mercantilizadas, donde los propios deportistas son asalariados y productos de compraventa (como ocurre en particular con los practicantes del fútbol), igualándose así el deporte a una modalidad del trabajo alienado ejecutado como medio de subsistencia. Por ello mismo el deporte pasa a ser un escenario más de la guerra de todos contra todos que es el capitalismo, donde el otro no pasa de un obstáculo que debe ser superado o un enemigo potencial del que hay que desconfiar. Junto a estas escenas de "comercio explícito" el deporte actual da periódicamente el espectáculo de nacionalismos infantiles y agresivos, precisamente en aquellas instancias en que supuestamente sería el vínculo de la "amistad entre los pueblos", como es el caso de las competencias continentales y los Juegos Olímpicos.

Y de tiempo en tiempo, a tono con el cariz de la vida individual fuera del deporte y con el propio perfil asumido por éste, ocurre la explosión de violencia abierta en los Estadios; y no necesariamente entre individuos de diversa nacionalidad y ni siquiera de diversos clubs.

\section{Individuo individualista, a-político y pasivo}

El individuo reducido a cuerpo es un ente que piensa durante 330 días en el mes de vacaciones que ha de culminar los once meses de trabajo alienado y este pensamiento no deja lugar para los molestos "por qué" de su forma de vida compartida con millones. Ese mes encierra toda la realización posible; la Polis es sinónimo de calles atestadas y violentas de las que en ese mes se logra huir; la Historia es algo que otros hacen a través de decisiones que la TV informa diariamente. Así, a la luz de la soledad cercada por la violencia, de la confusión del aturdimiento y la dispersión y de la reducción de la individualidad a la corporalidad hollywoodiana, surge la des-gregarización que se expresa en el a-politicismo y la pasividad histórica. Sin duda que a ese marco contextual puede agregarse el desencanto ante las promesas nunca cumplidas de una Historia leída con lentes deterministas y triunfalistas que la presentaban como destinada a instalar el paraíso en la Tierra. Pero sería ingenuo creer que ese desencanto se origina más en el fracaso y la inconsecuencia de los experimentos de postcapitalismo que en la frustración diaria generada por el "capitalismo real". Es en ella donde anida el desinterés creciente por los mecanismos reguladores de la democracia burguesa, que lleva a que menos de la mitad de los electores acudan a votar en las elecciones presidenciales norteamericanas. Allí echa raíces la progresiva dessindicalización entre los asalariados (al tiempo en que las entidades patronales a nivel nacional y su cartelización mundial, por ejemplo la del "Club de los Bancos acreedores del Tercer Mundo", van muy bien, igracias!). Así, donde reinaba la organización y movilización colectiva y la solidaridad, se instala el individualismo y la pasividad. A ese estado de cosas pertenece la expresión de lástima en los 
ojos y en la voz que hace algunos años usó una de mis alumnas de 18 años cuando profetizó: "Usted, profesor, es un ingenuo; piensa que algo puede cambiar".

Además del deporte, el esparcimiento se reduce para millones de individuos actuales a lo que ofrece la TV y el cine, y este último no infrecuentemente imita lo exhibido por la primera. Los programas de auditorio rivalizan en su afán de imbecilizar a los participantes y telespectadores. Y hay que decir que éstos, agobiados por todas las miserias antes descriptas se dejan hacer de buen grado. Las telenovelas repiten incansablemente la historia del "falso hijo-falsa hermana", del "amor prohibido entre un pobre y un rico" y del "¿quién mató a x?". Y es necesario constatar que los mismos individuos de marras disfrutan de esa comida en la que ni siquiera la salsa muda. ¿Qué decir de la mayoría de las películas sino que ellas son verdaderas lecciones de capitalismo? Quien lo dude que haga la experiencia de poner al azar alguna película hollywoodiana y verificar si en menos de diez minutos no aparece la palabra "dólar". En relación al disfrute de la violencia que exhalan creo pertinente la hipótesis que sostiene que aquél se asocia a un rito de conjuro mediante el cual la violencia real pudiera ser prevenida-alejada por la seudo-vivencia de la violencia representada. Es como un "curarse en salud", o aún un "enfermar ficticiamente" y por plazo preestablecido, para intentar escapar a la enfermedad real. Ahora bien, el mismo vehículo que propina al individuo tal tipo de "esparcimiento" es el que antes o después del programa de auditorio, la telenovela o la película, transmite las noticias que le reiteran la necesidad de tal rito ante la violencia "permanente e inevitable de la vida". Con lo que el círculo se cierra. Los individuos de los que venimos hablando son en buena proporción, y esto es un desafío mayor para la lucha ecomunitarista, individuos cobardes ante cualquier instancia de poder. Si la manifestación de tal cobardía ante el "jefe" en el lugar de trabajo es una vivencia que los humoristas satirizan con gusto (muchas veces sin sospechar que ella reside en última instancia en la característica propia del trabajo alienado consistente en la separación existente entre el productor y los medios de producción), otras instancias de tal manifestación no son muy propicias a que se las trate con humor o se las "folclorice". Me refiero a las manifestaciones cotidianas de cobardía que apoyan por acción u omisión, las más brutales formas de opresión y autoritarismo. Es un hecho que la mayoría de la población alemana apoyó a Hitler hasta el fin del III Reich; que la mayoría de los supuestos "comunistas" (muchos con carnet de la Juventud o del Partido y con su tierno pasado enraizado en los komsomoles) se apartó del comunismo cuando el mandamás de turno en la ex-URSS decidió que el futuro pertenecía al capitalismo.

Sin duda que en este último hecho no se puede descartar la existencia de la hipocresía y la "lengua de madera" usada antes de la mudanza (como lo confiesan abiertamente algunos para explicar que eran afiliados a las organizaciones comunistas no por ser comunistas de verdad sino para poder "subir en la vida", o sea para poder ocupar cargos de prestigio y mejor pagados); mas esta circunstancia, lejos de oponerse al hecho brutal que ahora presento lo confirma: 
la mayoría de los individuos de nuestro tiempo se comportan de forma cobarde ante las instancias de poder. Me refiero al contexto capitalista, y dentro de éste a la América Latina de hoy (por no manejar muchos detalles de lo que sucede en el día a día del capitalismo central), para destacar que aquella forma cobarde de comportamiento se mostró en la circunstancia de que, atacada en las fuentes de su subsistencia por políticas neo-liberales, la mayoría de los individuos pudo permanecer por un tiempo increíblemente pasiva. Y no hablo de masas analfabetas y sin tradición de lucha. Hablo también de sindicatos tradicionales y de profesores universitarios. Si antes se decía con tono despectivo de alguien: "lo único que lo mueve es el bolsillo", ahora hay que decir que ha sucedido por algunos años que la mayoría ni siquiera por su bolsillo fue capaz de moverse. Y lo curioso es que no se movieron aunque los autores de tales políticas fueran elegidos con los votos de esa mayoría, en relación a la cual las promesas de priorizar la atención gubernamental en las esferas del empleo, la salud, la educación y la vivienda se transformó en la práctica en sus contrarios. Todo sucede como si la indiferencia hacia los otros hubiera sido introyectada por esa mayoría como una increíble indiferencia cobarde hacía sí; y, como el avestruz de los dibujos, al verse en peligro, en vez de luchar, escondió la cabeza debajo de la tierra. Sin duda debe haber en la cobardía de la mayoría un singular proceso de regresión digno de estudio por los especialistas por cuanto es sabido que los niños tienen un comportamiento semejante a dicho avestruz cuando enfrentados a un peligro se tapan los ojos, creyendo sin duda que tal ceguera de su parte en relación a la amenaza redundará en la salvación respecto de esa misma amenaza, quizá por el hecho de hacerse no-visibles para ella. Fuera de la esfera financiera del salario y los gastos con educación, salud y vivienda, creo interesante destacar que esa cobardía se extiende a otras dimensiones de las relaciones con el poder establecido; el mismo que, repito, (supuestamente) ha emanado de la decisión mayoritaria de los mismos individuos que acusan luego el comportamiento ahora considerado.

\section{Violencia entre los oprimidos y fanatismo inter-comunitario}

Confirmando y ampliando la posibilidad de violencia entre los oprimidos que denunciaba Freire en su "Pedagogía del Oprimido", hoy asistimos a una orgía de tal violencia motivada especialmente por el tráfico y el consumo de drogas ilícitas y de drogas "lícitas" como el alcohol. Lejos de contrariar la cobardía antes descripta, el odio fanático y violento con el que vastos grupos se oponen a otros en el contexto inter-comunitario, no hace sino confirmar aquella cobardía. Lo más probable es que la gran mayoría de los integrantes de esos grupos prefieren y anhelan la convivencia pacífica con los integrantes del otro bando. Pero su cobardía les impide a cada uno en su bando contrariar la voluntad guerrera de los líderes de turno. En ese contexto los "ricos" EEUU y la "rica" Europa se cerraron a siete llaves para impedir la entrada en su territorio de los hambrientos que su 
propia política secular empuja hacia afuera del Tercer Mundo empobrecido y enfermo. Baluartes de la muralla que esa Europa yergue a toda prisa en nombre de la civilización occidental y cristiana son los "cabezas rapadas" y una abigarrada variedad de grupos y grupejos racistas y neonazis. Si esa misma Europa creía poder folklorizar las carnicerías inter-étnicas cuando del espacio tribal africano se trataba, esa actitud ya no cabe cuando las mismas se verificaron en uno de sus pilares culturales y también en el seno mismo de su geografía. Me refiero, por un lado, al conflicto que en Oriente Medio (y con el telón de fondo nada santo que significa el acceso de los países del capitalismo central a sus principales fuentes de abastecimiento de petróleo, situadas en el Golfo Pérsico) opone a Israel y a palestinos, y por otro, a la reciente guerra tripartita que aniquiló a Yugoslavia oponiendo a servios (comunistas y/u ortodoxos), croatas (católicos) y musulmanes (de Bosnia), y a la guerra que se traba entre Rusia y la pequeña Chechenia separatista.

Es interesante constatar que en medio del crecimiento galopante del desempleo aún en países aparentemente tan estables en su composición étnica surjan síntomas que parecen asimilados a esta agresividad intercomunitaria sin que se pueda descartar a priori una posible evolución violenta de su manifestación.

\section{La alternativa y postura ecomunitaristas. La superación de la alienación: comunismo, ecomunitarismo y socialismo del siglo XXI (ver López Velasco 2009, 2010 y 2012)}

En los Manuscritos de 1844 Marx caracterizó resumidamente el comunismo como

...retorno del hombre para sí en cuanto ser social, es decir, humano; retorno pleno, consciente y efectuado dentro de toda la riqueza de la evolución humana hasta el presente. Este comunismo es, como completo naturalismo=humanismo, como completo humanismo=naturalismo; es la verdadera solución del conflicto entre el hombre y la naturaleza, entre el hombre y el hombre, la solución definitiva del litigio entre existencia y esencia, entre objetivación y autoafirmación, entre libertad y necesidad, entre individuo y género. Es el enigma resuelto de la historia y sabe que es la solución (III 143).

Al fin del primer tomo de "El Capital" (que, recordémoslo, fue el único que Marx logró publicar en vida) nuestro autor presenta el paso al comunismo como sigue: "El monopolio del capital se convierte en grillete del régimen de producción que ha crecido con él y bajo él. La centralización de los medios de producción y la socialización del trabajo llegan a un punto en que se hacen incompatibles con su envoltura capitalista. Esta salta hecha añicos. Ha sonado la hora final de la propiedad capitalista. Los expropiadores son expropiados. El sistema de apropiación capitalista que brota del régimen capitalista de producción, y por 
tanto, la propiedad privada capitalista, es la primera negación de la propiedad privada individual, basada en el propio trabajo. Pero la producción capitalista engendra, con la fuerza inexorable de un proceso natural, su negación. Es la negación de la negación. Esta no restaura la propiedad privada ya destruida, sino una propiedad individual que recoge los progresos de la era capitalista: una propiedad individual basada en la cooperación de trabajadores libres, y en la posesión colectiva de la tierra y de los medios de producción producido por el propio trabajo". Y Marx remataba:

La transformación de la propiedad privada dispersa y basada en el trabajo personal del individuo en propiedad privada capitalista fue, naturalmente, un proceso muchísimo más lento, más duro y más difícil, que será la transformación de la propiedad capitalista, que en realidad descansa ya sobre métodos sociales de producción, en propiedad social. Allí se trataba de la expropiación de la masa del pueblo por unos cuantos usurpadores; aquí, de la expropiación de unos cuantos usurpadores por la masa del pueblo (I 699-700, hemos corregido la traducción cotejándola con el original alemán).

Por nuestra parte, sabedores por la experiencia histórica de que el paso al comunismo no es ni será tan "inexorable" ni tan "natural", ni tan "fácil" como lo creyó Marx, pero ampliando-precisando-actualizando la utopía marxiana a las esferas comunicativa, pedagógica, ecológica, erótica y política, hemos propuesto el ecomunitarismo. Recuérdese que llamo "Ecomunitarismo" al orden utópico poscapitalista (nunca alcanzable, pero indispensable horizonte histórico, guía de la acción) capaz de articularse en base a las tres normas de la Ética, y de mantenerse mediante la postura de seres humanos en actitud de liberación. El ecomunitarismo, en su dimensión productivo-distributiva, comunicativa, ecológica, pedagógica, política y erótica, retoma, actualizándola y completándola, la utopía marxiana del comunismo (ver López Velasco 2009, 2010 y 2012).

La economía ecológica y sin patrones que caracteriza al ecomunitarismo se rige por el principio "de cada uno según su capacidad y a cada uno según su necesidad, preservando los equilibrios ecológicos". Aquellas necesidades habrán de definirse y redefinirse consensualmente a la luz de las tres normas fundamentales de la ética.

La pedagogía ecomunitarista es la educación ambiental ecomunitarista, basada en la pedagogía problematizadora propuesta por Friere; esa educación incluye una educación sexual orientada hacia el libre, consensual y sano disfrute compartido del placer, y que supera el machismo, la homofobia y la condena a la masturbación; así esa educación es el pilar fundamental de la erótica de la liberación propia al ecomunitarismo.

La política de todos está basada en la democracia participativa (siempre que posible, directa) y protagónica, con rotación en la ocupación de los cargos repre- 
sentativos que se juzguen indispensables, y con la posibilidad dada a los electores de revocar el mandato de los electos.

En el ecomunitarismo, la comunicación es simétrica, apoyada en el cara-acara y las posibilidades que ofrece la Internet, así como los medios de comunicación que habrán de ser comunitarios y/o verdaderamente públicos.

Ese conjunto de espacios y acciones define el perfil de la marea ecomunitarista capaz de sumergir al capitalismo en el pasado de la historia (o, como dijo Marx, de la prehistoria humana).

\section{Prácticas políticas rumbo al Ecomunitarismo: Historia, Utopía y el socialismo del siglo XXI}

¿Cuál es el perfil de las prácticas que conforman el camino orientado por el horizonte ecomunitarista? Para responder a esta pregunta me permito algunas observaciones conjeturales basadas en nuestra reciente experiencia histórica.

Si hemos hecho un crudo análisis del comportamiento de las mayorías, no podemos obviar el hecho de que las perspectivas de cambio hacia el poscapitalismo echan sus raíces en minorías activas, capaces de constituirse en mayorías. Así por ejemplo surgió el embrión del "socialismo del siglo XXI" en Venezuela y Bolivia; en Venezuela una minoría organizada como movimiento bolivariano dentro del Ejército intentó sendos Golpes de Estado patrióticos en febrero y noviembre de 1992, que se saldaron por dos rápidas derrotas militares; pero su ejemplo y programa sedujo progresivamente a más y más sectores sociales, haciendo posible el triunfo electoral de Hugo Chávez en la elección presidencial de 1998; a partir de allí el programa anclado en las "tres raíces" (Bolívar, Simón Rodríguez y Zamora) se fue profundizando en su crítica al capitalismo, hasta llegar a proponerse la construcción del socialismo del siglo XXI a partir de 2005. A su vez en Bolivia, un antiguo pero minoritario, desde el punto de vista electoral, movimiento campesino-indígena que tenía como núcleo a los plantadores de coca, logró el apoyo del antiguo movimiento minero, y de algunos sectores medios, y esas antiguas minorías unidas lograron poner a Evo Morales en la presidencia del país en 2005; rápidamente la Bolivia de Morales aceptó también para sí el desafío-horizonte del socialismo del siglo XXI.

En 2005 nació en América Latina (en Venezuela, más precisamente) el Ilamado "socialismo del siglo XXI". A diferencia del Ilamado "socialismo real" (del siglo XX) esta propuesta defiende: a) una perspectiva intercultural (que reivindica la contribución de los pueblos indígenas, y de las comunidades negras), b) una perspectiva socioambiental que une la satisfacción de las necesidades humanas con la preservación-regeneración ecológica de la naturaleza no humana, c) una democracia participativa y protagónica que integra pero supera a la democracia representativa (burguesa) y en la que el poder constituyente (el cuerpo ciudadano) nunca transfiere su soberanía, pues la base del poder político es el poder 
popular directo, y la ciudadanía puede revocar el mandato de los electos para cargos públicos, d) una educación ambiental problematizadora, que integra una educación sexual orientada hacia una erótica de la liberación (que postula el goce del placer libremente compartido, y que supera el machismo, la homofobia y la condena a la masturbación), e) la libertad de expresión y prensa, combatiendo los latifundios mediáticos oligárquicos y multinacionales, y apostando a la prensa comunitaria y pública, f) la defensa armada a cargo de los propios ciudadanos, organizados en milicias (complementos de las fuerzas armadas regulares y destinadas a ser sus sucesoras), g) la progresiva realización de la Patria Grande querida por los Libertadores en América Latina, a través de la creación sucesiva del ALBA (Alianza Bolivariana para los Pueblos de Nuestra América), UNASUR (Unión de Naciones Suramericanas) y CELAC (Comunidad de Estados Latinoamericanos y Caribeños), y h) la realización efectiva del género humano, reuniendo a todos los seres humanos en una única familia (que aunque con roces esté signada por la cooperación mutua), superando a la actual ONU por superar los mecanismos de dominación por parte de los países capitalistas centrales que rigen en ella.

\section{Bibliografía}

AUSTIN, J. L. (1962). How to do things with words, Clarendon Press, London.

FREIRE, P. (1970). Pedagogia do Oprimido, Paz e Terra, Rio de Janeiro.

LÓPEZ VELASCO, S. (2009). Ética ecomunitarista, UASLP, San Luis Potosí, MéxiCO.

LÓPEZ VELASCO, S. (2010). El socialismo del siglo XXI en perspectiva ecomunitarista, UASLP, San Luis Potosí, México.

LÓPEZ VELASCO, S. (2012). Ideias para o socialismo do século XXI com visão marxiana-ecomunitarista, Editfurg, Rio Grande.

MARX, K. (1844). Ökonomische-Philosophische Manuskripte 1844, Rowohlt Taschenbuch Verlag, Hamburg, 1968. Manuscritos de Economía y Filosofía, Alianza, Madrid, 1970.

MARX, K. (1864-1894). Das Kapital [ 3 Bände], Ullstein, Frankfurt- Berlin, 1969. El Capital, Pueblo y Educación, La Habana, 1973, 1983. 